\title{
No toda apertura «en domo» de velo anterior de válvula mitral es debida a enfermedad reumática cardiaca
}

\author{
Not every "dome-shaped" anterior mitral valve veil aperture is due to rheumatic heart \\ disease \\ Javier Urmeneta-Ulloa ${ }^{1 *}$, José A. Cabrera ${ }^{1}$, Daniel Concepción Hernández ${ }^{2}$ y Vicente Martínez de Vega² \\ ${ }^{1}$ Departamento de Cardiología; ${ }^{2}$ Departamento de Radiología. Hospital Universitario Quirónsalud, Universidad Europea de Madrid, Madrid, España
}

Mujer de 64 años de edad remitida para realización de cardiorresonancia magnética (CRM). Valoración cardiológica inicial por disnea de esfuerzo, objetivándose en ecocardiografía transtorácica valvulopatía mitroaórtica, con apertura «en domo» de velo anterior de válvula mitral (VM) en probable relación con enfermedad reumática cardiaca, así como coartación aórtica posductal significativa. En CRM, secuencias cine-SSFP (Fig. 1), se observa único músculo papilar posterolateral (flechas gruesas amarillas) con cabezas supernumerarias, sobre el cual se insertan cuerdas tendinosas de ambos velos de VM (flechas delgadas amarillas), y en dicho contexto, apertura en «domo» de velo anterior («VM en paracaídas») (flecha

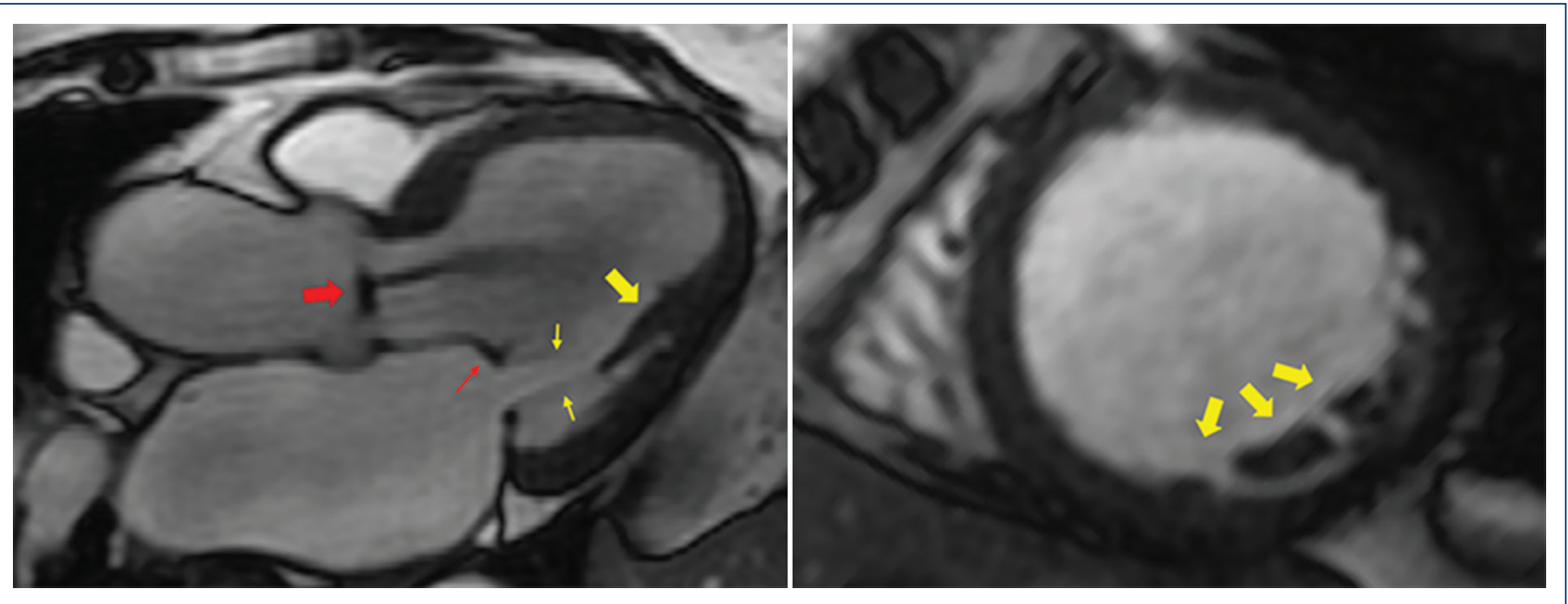

Figura 1. En cardiorresonancia magnética, secuencias cine-SSFP. Se observa único músculo papilar posterolateral (flechas gruesas amarillas) con cabezas supernumerarias, sobre el cual se insertan cuerdas tendinosas de ambos velos de VM (flechas delgadas amarillas), y en dicho contexto, apertura en "domo» de velo anterior ("VM en paracaídas») (flecha delgada roja), con estenosis mitral ligera e insuficiencia mitral severa. Al mismo tiempo, se presencia válvula aórtica bicúspide con insuficiencia aórtica moderada (flecha gruesa roja).

VM: válvula mitral

\section{Correspondencia:}

*Javier Urmeneta-Ulloa

E-mail: javierurmeneta@ hotmail.com CC BY-NC-ND (http://creativecommons.org/licenses/by-nc-nd/4.0/)
Disponible en internet: 19-05-2021 Arch Cardiol Mex. 2021;91(4):516-518 www.archivoscardiologia.com
Fecha de recepción: 08-02-2021 Fecha de aceptación: 16-03-2021 DOI: 10.24875/ACM.21000049 


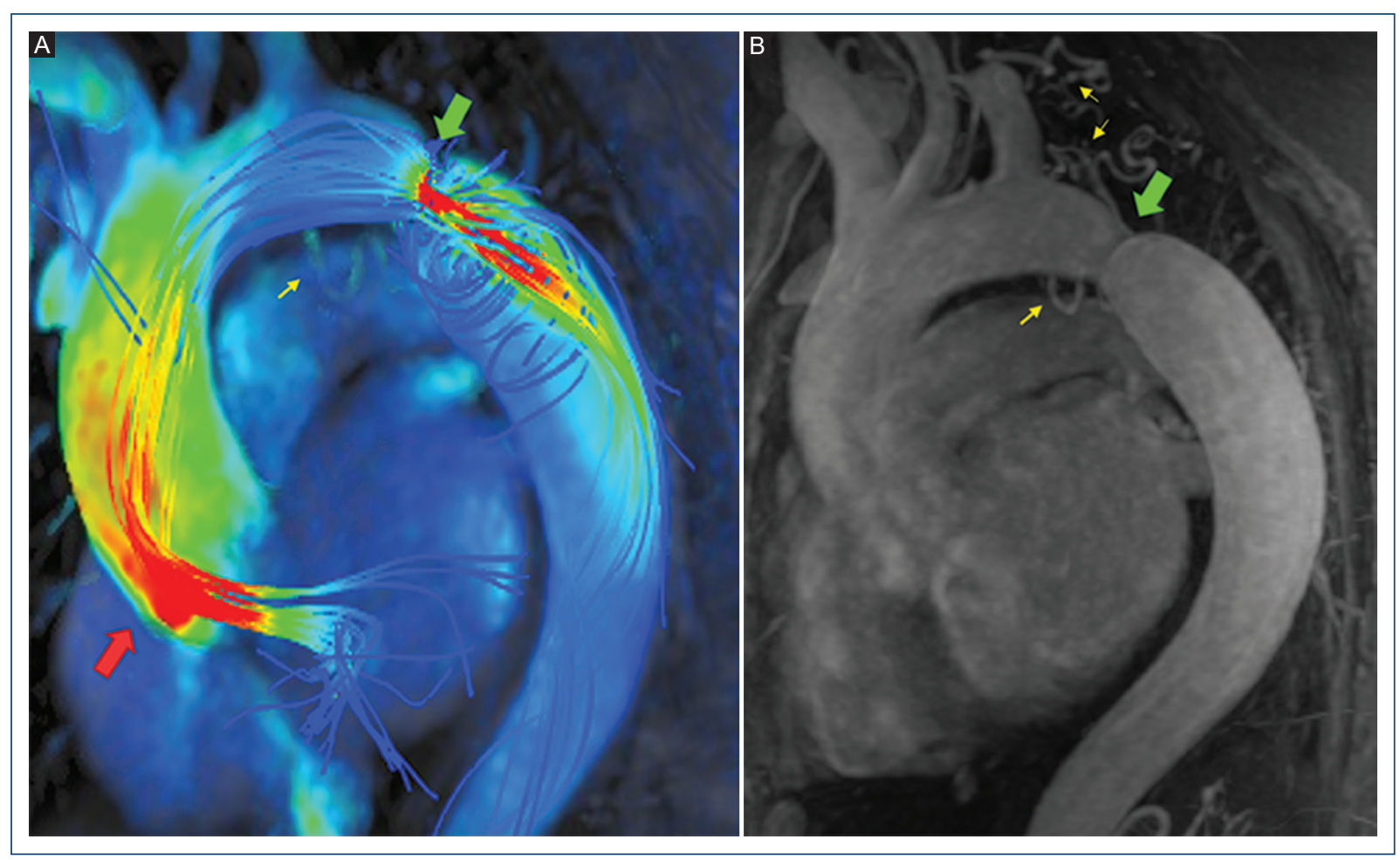

Figura 2. A: secuencia 4D-flow-CRM (flecha gruesa verde). B: angiografía-RM (flecha gruesa verde). Mediante 4D-flowCRM se evalúa el comportamiento de flujo en aorta torácica ascendente secundario a valvulopatía bicuspídea (flecha gruesa roja), así como pequeña circulación colateral (flecha delgada amarilla), presenciadas también en angiografíaRM (flechas delgadas amarillas).

CRM: cardiorresonancia magnética; RM: resonancia magnética.

delgada roja), con estenosis mitral ligera e insuficiencia mitral severa. Al mismo tiempo, se presencia válvula aórtica bicúspide con insuficiencia aórtica moderada (flecha gruesa roja). Finalmente, se objetiva coartación aórtica significativa valorando su comportamiento funcional/anatómico por medio de secuencia 4D-flow-CRM y angiografía-RM (Fig. 2). Mediante 4D-flow-CRM se evalúa igualmente el comportamiento de flujo en aorta torácica ascendente secundario a valvulopatía bicuspídea (flecha gruesa roja), así como pequeña circulación colateral (flecha delgada amariIla), presenciadas también en angiografía-RM (flechas delgadas amarillas). Los hallazgos previos fueron finalmente englobados en contexto de cardiopatía congénita tipo complejo de Shone, forma parcial/ incompleta.

El complejo/síndrome de Shone representa una anomalía congénita $(<0.7 \%)$ caracterizada por la presencia conjunta de VM en paracaídas, anillo supravalvular mitral, obstrucción al tracto de salida y coartación aórtica. Formas parciales/incompletas las constituyen la patología congénita de VM y al menos una lesión de tracto de salida ${ }^{1,2}$. La presencia simultánea de patología aórtica y apertura "en domo" de VM nos debe alertar sobre este infrecuente síndrome.

\section{Financiamiento}

La presente investigación no ha recibido ayudas específicas provenientes de agencias del sector públi$c o$, sector comercial o entidades sin ánimo de lucro.

\section{Conflicto de intereses}

Los autores declaran no tener conflicto de intereses.

\section{Responsabilidades éticas}

Protección de personas y animales. Los autores declaran que para esta investigación no se han realizado experimentos en seres humanos ni en animales.

Confidencialidad de los datos. Los autores declaran que han seguido los protocolos de su centro de trabajo sobre la publicación de datos de pacientes. 
Derecho a la privacidad y consentimiento infor-

mado. Los autores han obtenido el consentimiento informado de los pacientes y/o sujetos referidos en el artículo. Este documento obra en poder del autor de correspondencia.

\section{Bibliografía}

1. Aslam S, Khairy P, Shohoudi A, Mercier LA, Dore A, Marcotte F, et al. Shone complex: An under-recognized congenital heart disease with substantial morbidity in adulthood. Can J Cardiol. 2017;33:253-9.

2. Schaverien MV, Freedom RM, McCrindle BW. Independent factors associated with outcomes of parachute mitral valve in 84 patients. Circulation. 2004;109:2309-13 